\title{
Garlic and its Active Compounds: A Novel Strategy to Fight Diseases Through Modulating Biological Activities
}

\author{
Faris Alrumaihi*
}

\section{Faris Alrumaihi*}

Department of Medical Laboratories, College of Applied Medical Sciences, Qassim University, Buraydah, SAUDI ARABIA.

\section{Correspondence}

\section{Faris Alrumaihi}

Department of Medical Laboratories, College of Applied Medical Sciences, Oassim University, Buraydah, SAUDI ARABIA

E-mail: f_alrumaihi@qu.edu.sa

History

- Submission Date: 24-06-2020;

- Review completed: 01-08-2020;

- Accepted Date: 05-08-2020

DOI : 10.5530/pj.2020.12.201

Article Available online

http://www.phcogj.com/v12/i6

Copyright

(C) 2020 Phcogj.Com. This is an openaccess article distributed under the terms of the Creative Commons Attribution 4.0 International license.

\begin{abstract}
Throughout history, many plants and their products have been widely used as medicines for the prevention and treatment of different diseases in many cultures. Garlic (Allium sativum), is commonly used as a spice and traditionally used for its medicinal value since ancient times. Recent studies support the effects of garlic and its extracts in a wide range of applications. Due to the presence of sulfur containing compounds, high trace mineral content and enzymes, garlic has been reported to have implications in disease management and play a role as anti-diabetic, anti-microbial, anti-obesity, anti-oxidant and anti-tumor, dyslipidaemia effect, neuroprotective, cardio-preventive and photo-protection effects. It contains various active compound such as allicin, ajoene, diallyl disulfide and S-allyl-cysteine that modulates various biological cascades and prevent the pathogenesis. This review illustrates the role of garlic and their active ingredients in the health management based on in vivo and in vitro studies.

Key words: Garlic, Allicin, Ajoene, Diallyl disulfide, Anti-oxidant, Anti-cancer, Anti-inflammatory effect.
\end{abstract}

\section{INTRODUCTION}

The increasing incidence of diseases is a huge burden on any country, which needs to be addressed in a priority basis to reduce the incidences, morbidity and mortality. Alternative medicines and treatment based on natural products have gained a role in health management over the last few years. Natural products or various compounds of medicinal plants play an important role in the management of diseases including cure and inhibition through modulating various biological activities. Treatments based on natural products have been demonstrated to play a significant role in curing diseases without any adverse effect on the body and physiological process. Moreover, alternative medicines and natural products derived from a variety of sources are safe, inexpensive and also do not show any adverse effect on cell signalling pathways and biological cascades. In this regard, garlic and its active compounds have shown a potential tendency to cure many diseases t. Garlic and its active compounds such as allicin, ajoene, diallyl sulfide (DAS), diallyl disulfide (DADS), s-allyl cysteine and, diallyl trisulfide (DATS) (Figure 1) show a potent role in modulating the various cell signalling pathways. In this review, we discussed laboratory based experiment of the role of garlic in management of diseases through modulating various biological activities. ${ }^{1-7}$ Besides, we discussed different strategies that improve the therapeutic efficiency of drugs, bioavailability, absorption and metabolism of garlic active compounds.

\section{PHARMACOLOGICAL ACTIVITIES} OF GARLIC AND ITS COMPOUNDS

Garlic is a mixture of various active compounds and such compounds play significant role in diseases prevention and treatment (Figure2).

\section{Antioxidant activity}

Reactive oxygen species and free radicals have been documented to be the main offenders in the development and progression of diseases and contribute significantly to pathogenesis. Thus, inhibition of free radical formation can be a very significant step against pathogenesis. In this regard, several previous studies have indicated the vital role of natural products in the inhibition of pathogenesis of diseases through their antioxidant's properties. Natural products such as thymoquinone, curcumin, and garlic have proven their role in the cure of the diseases. Garlic and its active compounds showed a therapeutic role and inhibits the disease progression through its antioxidant as well as free radical scavenging property by neutralising the reactive oxygen species (Figure 2, Table1). A pioneering study has indicated that diallyl trisulfide, a component of garlic can protect from reactive oxygen speciesmediated apoptosis. ${ }^{1}$ Further, diallyl disulphide has been reported to enhance the antioxidant enzyme activity significantly and restore the glutathione content in rats fed on a high fat diet. ${ }^{2-6}$

Garlic extract has been shown to considerably inhibit superoxide production and aged garlic extract has been suggested to be valuable for inhibiting diseases related with reactive oxygen species. ${ }^{7}$ Garlic oils and extracts are associated with many health-benefit activities, including a protective capacity against oxidative stress induced DNA damage, increased hydrogen peroxide scavenging activity, as well as it potential to reduce the bioactivity of carcinogens and tumor cell proliferation..$^{8-21} \mathrm{~A}$ study was performed to investigate the antioxidant properties 


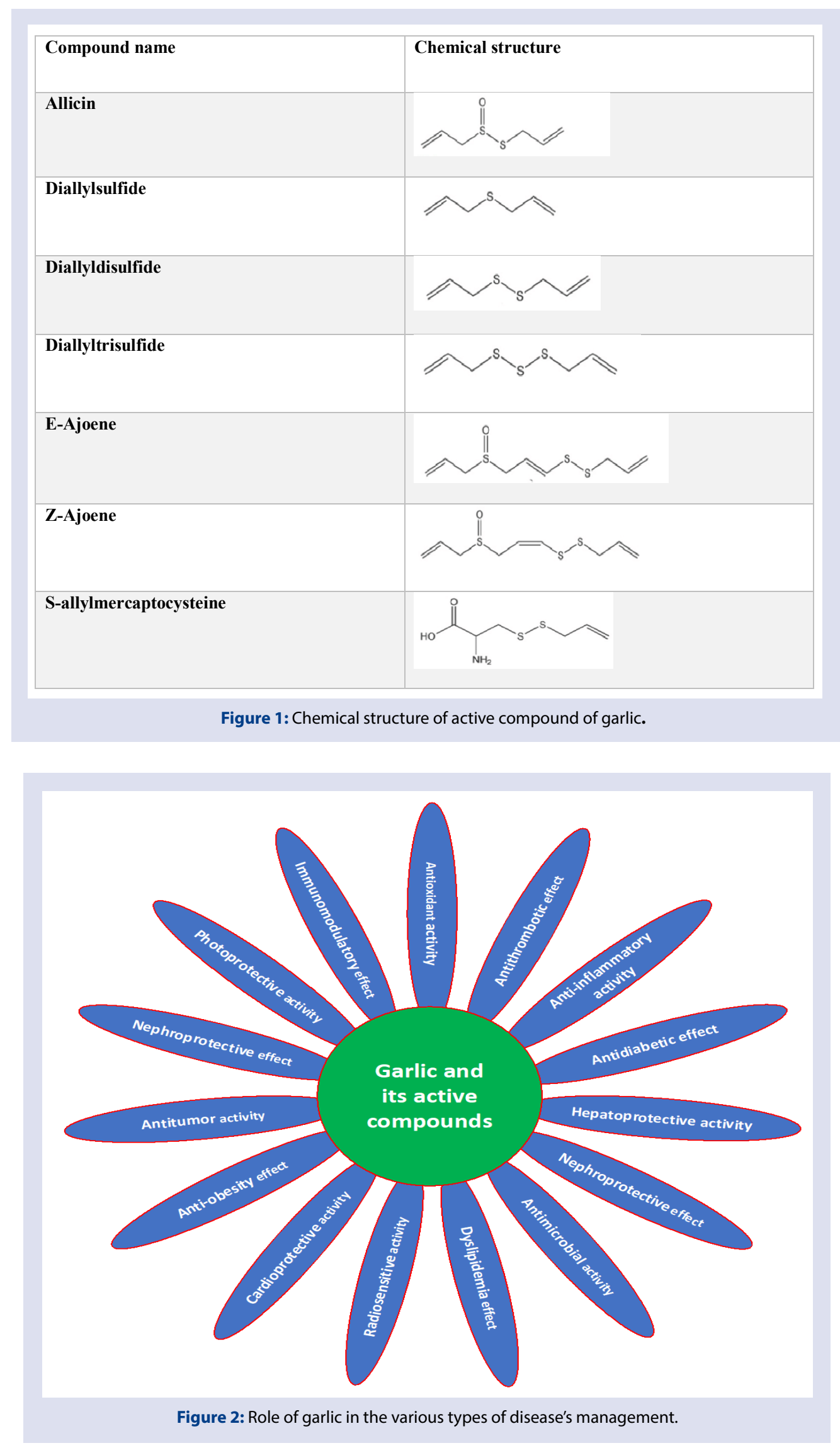


Table 1: Pharmacological activities of garlic and its active compounds.

\begin{tabular}{|c|c|c|c|}
\hline Activity & Compound & Outcome of the study & Refs. \\
\hline Antioxidant & Allicin & Scavenged superoxide and allicin suppressed the formation of superoxide & 7 \\
\hline Antioxidant & Fresh and aged garlic & Aged garlic showed more potent antioxidant & 8 \\
\hline Antioxidant & Ajoene & Ajoene increases PKC delta-dependent Nrf2 activation & 10 \\
\hline Antioxidant & S-allylcysteine & S-allylcysteine increased antioxidant enzymes activity & 11 \\
\hline Antioxidant & Diallyl disulphide & Antioxidant enzyme activity was meaningfully improved & 2 \\
\hline Anti-inflammatory & Garlic extract & IL-10 production increased significantly and TNF-alpha decreased significantly & 3 \\
\hline Anti-inflammatory & S-allyl cysteine & $\begin{array}{l}\text { S-allyl cysteine, an ingredient of garlic was noticed to decrease oxidative stress } \\
\text { and inflammation }\end{array}$ & 30 \\
\hline Anti-inflammatory & Garlic extract & Garlic extract shows role in inflammation & 31 \\
\hline Anti-diabetic & Raw garlic & Serum glucose levels in fructose feeding rats was knowingly decreased & 39 \\
\hline Anti-diabetic & Garlic extract & $\begin{array}{l}\text { Administration of extract of garlic showed role in the reduction of the } \\
\text { hyperglycemia, polyphagia and linked weight loss }\end{array}$ & 40 \\
\hline Anti-diabetic & Alliin & Alliin treatment increased insulin sensitivity & 43 \\
\hline Anti-diabetic & S-allyl cysteine sulphoxide & $\begin{array}{l}\text { S-allyl cysteine sulphoxide decreased significantly the concentration of blood } \\
\text { glucose and activities of serum enzymes }\end{array}$ & 44 \\
\hline Hepatoprotective & S- allyl cysteine & $\begin{array}{l}\text { S- allyl cysteine was very effective in preventing gastric damages via significant } \\
\text { decreases in macrophage infiltration }\end{array}$ & 52 \\
\hline Hepatoprotective & Diallyl trisulfide & $\begin{array}{l}\text { Diallyl trisulfide pretreatment meaningfully improved serum biochemical and } \\
\text { histopathological alterations reflecting hepatic dysfunction }\end{array}$ & 53 \\
\hline Anti-microbial & Diallyl disulphide & Diallyl disulphide showed noteworthy antibacterial activity & 57 \\
\hline Anti-microbial & Diallyl disulfide & Dose-dependent bactericide effects on bacterial cultures & 58 \\
\hline Anti-microbial & Allicin & Allicin is effective in inhibition of the growth in hyphal cells & 60 \\
\hline Anti-microbial & Diallyl sulphide & $\begin{array}{l}\text { Diallyl sulphide provokes strong antimicrobial activity and may have } \\
\text { applications for reducing the prevalence of this microbe in foods }\end{array}$ & 63 \\
\hline Dyslipidemia & Garlic extract & $\begin{array}{l}\text { Dietary supplementation with garlic extract has beneficial effects on the lipid } \\
\text { profile }\end{array}$ & 66 \\
\hline Dyslipidemia & Garlic-powder tablets & $\begin{array}{l}\text { Garlic tablets showed effective role in the treatment of hyperlipidaemia by } \\
\text { lowering total cholesterol }\end{array}$ & 68 \\
\hline Cardio preventive & Garlic & Decrease in systolic blood pressure and decrease in diastolic blood pressure & 72 \\
\hline Cardio preventive & Garlic extract & Garlic extract is superior to placebo in lowering blood pressure & 73 \\
\hline Anti-obesity & Diallyl disulfide & $\begin{array}{l}\text { Diallyl disulfide in mixture attenuated high-fat/high-sucrose diet-induced } \\
\text { adipose increase }\end{array}$ & 78 \\
\hline Anti-obesity & Garlic extract & Feeding high fat diet-fed mice with garlic extract decrease body weight & 80 \\
\hline Anti-tumour & Diallyl disulphide & Diallyl disulphide reduced cell viability & 84 \\
\hline Anti-tumour & Diallyl disulphide & Diallyl disulphide were establish to block the metastasis & 86 \\
\hline Anti-tumour & Alliin & $\begin{array}{l}\text { Alliin inhibited proliferation of gastric carcinoma cells via decreasing the cell } \\
\text { viability }\end{array}$ & 89 \\
\hline Anti-tumour & Allicin & $\begin{array}{l}\text { Allicin induce apoptosis of the cells in a dose dependent and increase the } \\
\text { proportion of cells in the } \mathrm{G}_{2} / \mathrm{M} \text { phase }\end{array}$ & 93 \\
\hline Neuroprotective & Allicin & $\begin{array}{l}\text { Allicin significantly reduced edema and apoptotic neuronal cell death in } \\
\text { injured cortex }\end{array}$ & 96 \\
\hline Neuroprotective & Allicin & Allicin reduced cerebral infarction area, neuronal apoptosis, TNF- $\alpha$ levels & 99 \\
\hline Photo protective & Garlic & $\begin{array}{l}\text { Administration of garlic reduced the coarse wrinkle formation and, UV-induced } \\
\text { dorsal skin }\end{array}$ & 104 \\
\hline Immunomodulatory & Fructans & Fructans displayed mitogenic activity and activation of macrophages & 108 \\
\hline Anti-nephrotoxicity & Garlic extract & $\begin{array}{l}\text { Extract prevented the gentamicin-induced increase in the renal levels of } \\
\text { oxidative stress markers }\end{array}$ & 113 \\
\hline Anti-nephrotoxicity & Allicin & Allicin showed significant nephroprotective effects & 114 \\
\hline Reproductive system & Garlic extract & $\begin{array}{l}\text { Treatment with vitamin } \mathrm{E} \text { and garlic extract resulted in a significant increase in } \\
\text { sperm motility and viability }\end{array}$ & 116 \\
\hline Anticoagulant & Diallyl trisulfide -rich garlic oil & Garlic oil supplement meaningfully prolonged bleeding time and thrombin time & 119 \\
\hline Anticoagulant & $\begin{array}{l}\text { Diallyl disulphide and diallyl } \\
\text { trisulphide }\end{array}$ & $\begin{array}{l}\text { Diallyl disulphide and diallyl trisulphide, constituents of garlic oil, showed } \\
\text { antiplatelet activity }\end{array}$ & 120 \\
\hline Radiosensitization & Garlic extract & $\begin{array}{l}\text { Combination of extract and radiotherapy significantly induced apoptosis in } \\
\text { G2/M stage }\end{array}$ & 121 \\
\hline
\end{tabular}


of garlic compounds such as alliin, allyl cysteine, allyl disulfide, and allicin. Results confirmed that alliin scavenged superoxide and allicin suppressed the formation of superoxide through the xanthine/xanthine oxidase system, probably via a thiol exchange mechanism and alliin, allyl cysteine, and allyl disulfide all scavenged hydroxyl radicals. Moreover, this finding based on result concluded that allyl disulfide, alliin, allicin, and allyl cysteine showed different forms of antioxidant activities as protective compounds against free radical damage. ${ }^{22}$ Antioxidative and antibacterial properties of fresh garlic and aged garlic was evaluated. The findings of the study revealed that aged garlic showed more powerful antioxidant properties than fresh garlic. ${ }^{23}$ Allicin, an active compound of garlic prevented the lipid peroxidation of liver homogenate in a concentration-dependent manner. ${ }^{24} \mathrm{~A}$ pioneer study results revealed that ajoene from garlic increases PKC delta-dependent Nrf2 activation, which may defence cells from oxidative stress. ${ }^{25}$ Another finding reported that S-allylcysteine showed increased glutathione peroxidase, glutathione reductase, catalase and superoxide dismutase activities and increase in the activity of antioxidant enzymes. ${ }^{26} \mathrm{~A}$ study was performed based on gentamicin toxicity in rats and result confirmed that significant increase in myeloperoxidase and lipid peroxidation levels was observed, that was reduced after treatment with diallyl sulfide. Moreover, gentamicin-induced rats showed a significant decrease in the activities of various antioxidant enzymes such as superoxide dismutase, catalase, glutathione peroxidase, glutathione reductase and Quinone reductase that was increased after treatment with diallyl sulfide. ${ }^{27}$ Another study finding revealed that diallyl trisulfide protects against hyperglycemia-induced reactive oxygen species-mediated apoptosis. ${ }^{1}$ Diallyl disulphide, an ingredient of garlic oil, as an antioxidant agent was evaluated. Finding demonstrated that antioxidant enzyme activity was meaningfully improved whereas glutathione content was markedly restored in animals fed on a high fat diet concurrently with diallyl disulphide. ${ }^{2}$

\section{Anti-inflammatory activity}

Inflammation is an important factor in the pathogenesis of many diseases. The anti-inflammatory activity of several natural products has been noticed in in-vivo and in-vitro studies. It has been seen that garlic and their active compound have preventive activity against diseases because of its anti-inflammatory activity. It has been reported in a study that garlic extract in the treatment of patients with inflammatory bowel diseases, inhibit monocyte interleukin-12 production considerably. ${ }^{3}$

A study has reported that garlic inhibited the lipopolysaccharide -induced dimerization of Toll-like receptors ${ }^{4}$, leading to the inhibition of activation of NF-kappa B as well as the expression of cyclooxygenase 2 and inducible nitric oxide synthase. ${ }^{28,13}$ Garlic and its sulphur compounds show as an anti-inflammatory activity through inhibition of production of nitric oxide and the expression of the pro-inflammatory cytokines (Table 1). Another study results support aged garlic extract antioxidant, anti-inflammatory, and antimicrobial effectiveness revealed through the healing of the gastric tissue damage. ${ }^{29}$ In the support of garlic, it was reported that caffeic acid and S-allyl cysteine, an ingredient of garlic was noticed to decrease oxidative stress and inflammation..$^{30}$ Treatment with Fresh and heated raw garlic extracts (FRGE and HRGE) significantly decrease the LPS-induced increase in the pro-inflammatory cytokine concentration and NO through HO-1 upregulation in RAW 264.7 macrophages. ${ }^{31}$

However, monocyte Interlukin-10 production was found to be increased significantly whereas monocyte tumor necrosis factoralpha, Interleukin-6, and TNF-alpha decreased meaningfully in the presence of garlic extract. ${ }^{3}$ Additionally, alliin, an active compound of garlic prevents the increase of genes and proteins related to the proinflammatory state and showed clinically valuable anti-inflammatory effects. ${ }^{32,4}$ It has been confirmed on the basis of in vitro studies that garlic extract does suppression of the production of leukocyte inflammatory cytokines including tumor necrosis factor- $\alpha$, interleukin $-1 \alpha$, IL- 6 , and interferon- $\gamma$ and displays a beneficial potential in the treatment of inflammatory bowel disease. ${ }^{12}$ Natural products play a role in the regulation of cyclooxygenase enzymes activity. Garlic active ingredient such as diallyl disulfide, diallyl sulfide and alliin reduced inflammation during dengue virus infection and show that this reduction is due to the effects on the oxidative stress response. ${ }^{33}$ Pre-treatment with garlic powder extract showed role in the reduction of proinflammatory cytokines interleukin beta and tumour necrotic factor. ${ }^{34}$

\section{Anti-diabetic effect}

Studies based on laboratories have revealed that natural products play a promising role in the management of diabetes mellitus. In this regard, garlic and its compounds also have widely recognized to have a potential role in diabetes management. The antidiabetic effect of garlic extract has been investigated through various studies. The administrations of the garlic extract have been documented to decrease serum glucose, total cholesterol, and triglycerides levels. On the other hand, serum insulin was found to be increased in diabetic rats. ${ }^{35}$ Another study, antioxidant and anti-inflammatory effects of garlic oil were investigated. The finding had shown that oil of garlic enhanced insulin sensitivity and oral glucose tolerance in a dose-dependent manner and the antidiabetic effect of garlic oil was documented to ameliorate oxidative stress. ${ }^{36}$ The treatment with aged garlic extract has been shown to reverse the diabetic changes. The levels of targeted parameters of diabetes were significantly lowered in a dose-dependent ameliorative action of garlic extract. ${ }^{37}$ In diabetic rats, raw garlic revealed a beneficial effect in backing proteinuria in addition to reducing blood sugar, cholesterol and triglycerides. ${ }^{38}$ In another study on diabetic rats, the effects of raw garlic on insulin resistance, connected metabolic syndrome and oxidative stress were examined. Results demonstrated that the diabetic group had a noteworthy increase in blood glucose levels as compared to the control group. While the serum glucose levels were meaningfully reduced after the administration of garlic in fructose feeding rats. ${ }^{39}$ In streptozotocin treated animals, the administration of garlic extract showed the reduction of various parameters of diabetes including hyperglycemia, polydipsia, polyphagia and linked weight loss. ${ }^{40}$ The role of garlic oil and diallyl disulfide on glycemic control and renal function examined. Finding has demonstrated that long-term treatment of diabetes with garlic oil progress oral glucose tolerance and renal function in diabetes. ${ }^{41}$ Besides, garlic compound has also shown to improve oral glucose tolerance and insulin secretion was meaningfully increased. In addition to this, glycogen formation from glucose by the soleus muscle in the presence of insulin was considerably improved after treatment with both garlic compounds. ${ }^{42}$ Further, Jhai and colleagues investigated the preventive effect of alliin, a compound from garlic against metabolic risk factors. The results demonstrated the improvement of glucose homeostasis and increased insulin sensitivity in the diet induced obese mice by treatment with alliin. ${ }^{43}$ Recent report exhibited that administration of S-allyl cysteine sulphoxide, a compound from garlic decreased considerably the concentration of serum lipids, blood glucose and activities of enzymes. ${ }^{44}$

\section{Hepatoprotective effect}

Several natural products have been reported for their role as hepatoprotectant without any side effects. The result of a pioneer study has demonstrated that pre-treatment with garlic extract had a protective effect. Additionally, the prophylactic role of extract ulcers was initiated via decreasing oxidative stress and glutathione and nitric oxide. ${ }^{45}$ Another study results indicated that garlic extract had gastroprotective effects by noteworthy healing the damage of gastric mucosa and reduction in the total microbiome. ${ }^{46} \mathrm{Garlic}$ extract by lactic acid bacteria ameliorates liver injury through preventing oxidative stress-mediated 
apoptosis ${ }^{47}$ and garlic extract has hepatoprotective effects and advocates that garlic supplementation might be a one of the good adjuvant therapy for the management of liver injury. ${ }^{48}$ Naji and colleagues have reported that administration of clove garlic had a significant reductive effect on liver function enzymes including serum alkaline phosphatase, aspartate aminotransferase and alanine aminotransferase levels and it also had been reported to play role in the improvement of some histological parameters. ${ }^{49}$ Besides, a significant increase of lipid peroxidation and decreased liver antioxidant enzyme levels was noticed in hepatitis rats and pre-treatment with allicin, the chief ingredient of garlic stopped such types of changes. ${ }^{50}$ Administration of S-allyl cysteine to animals demonstrated a decrease in the expressions of nuclear factor-kappa B, tumor necrosis factor $\alpha$ and finding showed that S-allyl cysteine had a protective effect on the liver cells against free radical damage. ${ }^{51} \mathrm{~S}$ - allyl cysteine was very effective in preventing gastric damages in a low dose due to the significant decrease in macrophage infiltration and its curative action. In addition, indomethacin-induced expressions of inflammatory mediators were considerably attenuated with S-allyl cysteine in accordance with histone deacetylator inhibition. ${ }^{52}$ Another study result confirmed that diallyl trisulfide pre-treatment meaningfully improved as-induced serum biochemical and histopathological alterations showing hepatic dysfunction. ${ }^{53} \mathrm{~A}$ pioneer study result showed that the modulatory effect of garlic oil on hepatic drug-metabolizing enzymes can be due to its allyl sulfide components. ${ }^{54}$

\section{Antimicrobial effect}

Medicinal plants or their active compounds play a vital role in health management through its antimicrobial activity (Table 1). Active components of herbs have shown their role to kill the bacteria or inhibit the growth of microbes. Some studies have shown that garlic has the capacity to kill various types of pathogens and thus, may inhibit the pathogenesis. A study based on findings concluded that garlic extract has antibacterial properties in hamburger. Furthermore, garlic extract can be used both as a flavour as well as a natural additive. ${ }^{55}$ A study was performed to evaluate its antibacterial activity of garlic extract in vitro and the results confirmed the concentration dependent antibacterial activity of extract ${ }^{56}$ and diallyl disulphide, an active of garlic had shown significant antibacterial activity. ${ }^{57}$ The finding of an important study showed that there was decreased $\mathrm{N}$-acetyltransferase activity in Helicobacter pylori cytosols and suspensions with increased levels of diallyl sulfide or diallyl disulfide components from garlic and these components were reported to have dose-dependent bactericide effects on bacterial cultures. ${ }^{58}$ Niosomal formulation of diallyl sulfide was developed and its efficacy against experimental candidiasis was evaluated. It was reported that niosomal formulation of diallyl sulfide meaningfully reduced fungal load and mortality in treated swiss albino mice. ${ }^{59}$ Diallyl disulphide acts as a pro-oxidant to Candida species and therefore might act as a strong antifungal in the management of candidiasis. ${ }^{61}$ Study based on diallyl disulphide reported that diallyl disulphide was an effective antifungal agent that can lead to cell death in Candida ${ }^{46}$ Pure allicin has been shown to be effective in inhibition of the growth in hyphal cells and it could be used as alternatives in treatment of dermatophytosis. ${ }^{60}$ Methicillin-resistant Staphylococcus aureus isolates have been found to be susceptible to allicin. ${ }^{19}$ Besides, allicin and other thiosulphinates from garlic extract, are also recognised to possess antimicrobial activity because of their potential to inhibit Acetyl-CoA synthase. ${ }^{20,21}$ The inhibitory effect of two active compounds of garlic such as diallyl sulphide and diallyl disulphide against meticillin-resistant Staphylococcus aureus infection in diabetic mice was evaluated. Meticillin-resistant Staphylococcus aureus infection meaningfully increased malondialdehyde levels in the kidney and spleen and these levels were considerably decreased by treatment with garlic compound. Moreover, finding revealed that garlic active compounds could deliver various protective functions against infection in diabetic mice. ${ }^{62}$ Another study based on finding it was proven that diallyl sulphide provokes strong antimicrobial activity. ${ }^{63}$

\section{Dyslipidemia effect}

A clinical trial was made on thirty volunteer individuals with blood cholesterol more than 245 milligrams per decilitre. Forty-five days of garlic use demonstrated that the mean of blood total cholesterol triglycerides was reduced considerably. ${ }^{64}$ The role of the use of garlic on platelet thromboxane production was examined. After the use of garlic, reduction of serum cholesterol and reduction in serum thromboxane was noticed. ${ }^{65} \mathrm{~A}$ study comparing the effect of garlic extract with placebo on blood lipids was performed. Study based on finding concluded that dietary supplementation using garlic extract has constructive effects on the lipid profile and blood pressure.$^{66}$ Result established that treatment with garlic extract and dietary advice did not show any noteworthy changes in lipid levels in subjects. The effects of garlic on blood lipids and blood coagulation parameters in hyperlipemic patients were studied and results showed that not any dosage of dried garlic showed an important effect on any of the parameters measured. ${ }^{67}$ The effect of the tablet of garlic-powder in the treatment of hyperlipidaemia was investigated. It was reported that tablets of garlic have been revealed to be effective in the treatment by reducing total cholesterol values and triglyceride values. ${ }^{68}$ The subjects were given a fat-rich diet for seven days and on the eighth day the fasting blood was analysed. The serum cholesterol, serum triglycerides, and serum total lipids were considerably increased as compared to normally fed diet. When the garlic was substituted in fat-rich diet, the garlic considerably reduced the serum cholesterol and serum triglycerides. ${ }^{69}$

\section{Role in hypertension/ Cardio-preventive}

The role of allicin on hypertension and cardiac functions has been examined. It was noticed that allicin treatment reduces hypertension and plays a role in the enhancement of the renal and cardiac dysfunctions. ${ }^{70}$ The effect of garlic juice on the rat heart in ischemia- reperfusion was evaluated. Results demonstrated that juice has a vasodilator activity and also showed a role in the protection of the isolated ischemic heart when it was given in reperfusion. ${ }^{71} \mathrm{~A}$ meta-analysis on the effect of garlic on the blood pressure was performed. It showed the decrease in systolic blood pressure and decrease in diastolic blood pressure as compared with placebo. ${ }^{72}$ The effect, tolerability, and acceptability of aged garlic extract as an adjunct treatment to current antihypertensive medication in patients with treated, but uncontrolled, hypertension was examined. The result of the study concluded that the extract is greater to placebo in decreasing systolic blood pressure correspondingly to current first line medications in patients with treated but uncontrolled hypertension. ${ }^{73}$ Earlier study has advocated that the antihypertensive activity of garlic is due to its prostaglandin-like effects that reduce peripheral vascular resistance. ${ }^{74}$ The hypocholesteremic activity of garlic was evaluated through the incorporation of garlic powder at different dose levels in an atherogenic diet fed to rats. The result confirmed the garlic powder lower serum cholesterol level. ${ }^{75}$ The effect, dose-response, tolerability and acceptability of different doses of aged garlic extract as an adjunct treatment to current antihypertensive medication in patients with uncontrolled hypertension was checked by Reid and co-workers. Result confirmed that mean systolic blood pressure was considerably reduced in the garlic-2-capsule group compared with placebo, and reached borderline significant reduction in the garlic-4-capsule group at eight weeks. ${ }^{76}$ The study conducted by Cruz and co-workers indicated the association between antihypertensive and renoprotective effects of S-allyl cysteine and garlic extract with their antioxidant properties and that they might be used to ameliorate hypertension and delay the progression of renal damage. ${ }^{77}$ 


\section{Anti-obesity effect}

Recently several findings revealed that natural products or active compounds of medicinal plants have the potential to counteract obesity. The currently used drugs that target weight loss are effective but show adverse effects on several physiological processes. In this regard, garlic and its various ingredients have shown the potential to counteract obesity. Bae and colleagues have reported that diallyl disulfide has the ability to potentiate the anti-obesity effect of green tea in high-fat/highsucrose diet-induced obesity. Further, diallyl disulphide up-regulates the level of phosphodiesterase 5 in adipose tissues disulfide. ${ }^{78}$ In 2018, Yang et al. examined the obesity and hypolipidemic effects of garlic oil and onion oil on serum lipid levels in rats model fed with high fat diet. It was reported that garlic oil and clove oils suppress the body weight gain induced by high fat diet. ${ }^{79}$ Lee and colleagues evaluated the anti-obesity effects of garlic extract diet-induced obese mice. Result confirmed that feeding mice with high fat diet with garlic extract showed decrease in the body weight as to compare to a high fat diet. ${ }^{80}$ Study conducted by Zhang and co-workers in obese rats concluded that garlic oil had a substantial anti-obesity effect on obese rats because it showed the ability to decrease the body weight and to protect the liver damage.$^{81}$ In 2011, the anti-obesity effect of garlic was examined in diet-induced obese mice. It was found that dietary garlic had the potential role in both, the reduction of body weight as well as a mass of various adipose tissue deposits. Further, dietary garlic also improved the abnormal plasma and liver lipid profiles. ${ }^{82}$

\section{Anti-tumour effect}

The antitumor effect of natural compounds has been established and their effects have been noticed in the killing of cancer cells. Natural products show a chemopreventive effect through modulating various cellular and molecular pathways. However, natural products-based treatment will be one of the good options in the management of cancer. Natural products in the combination of existing drugs has confirmed that the drug activity becomes enhanced by natural products. Garlic and its active compounds have been reported to show significant role in the prevention of cancer because of its ability to inhibit the carcinogenesis process including initiation, promotion and progression (Figure 3).
They show anti-tumour effects because they have the potential to module various cell signalling pathways. In this regard, the previous findings reported that allicin, a compound of garlic inhibited the growth of cancer cells and induced the formation of apoptotic bodies and nuclear condensation in cancer cells. ${ }^{5}$ Besides, another study demonstrated that ajoene, another component of garlic might induce apoptosis in leukemic cells via stimulation of peroxide production and activation of nuclear factor $\mathrm{Kb} .^{6}$

Two active compounds of garlic including diallyl disulfide (DADS) and diallyl trisulfide (DATS) exhibit anti-cancer activities because they are able to promote apoptosis as well as arrest the cell cycle. ${ }^{14-16}$ Another study result reported their ability to proliferate SGC-7901 gastric cancer cells and to block the cell cycle in the G2/M-phase. ${ }^{17}$ Some studies based on animal models have exhibited that sulfuric compounds of garlic extract, slightly reduced the incident rates and severity of the tumor formation induced by $\mathrm{N}$-nitroso compounds. ${ }^{18}$ Diallyl disulphide was found to induce apoptosis in the breast-cancer cell line via regulating the cell-cycle growth phases in a way that increases the sub- $\mathrm{G}_{0}$ population and significantly pauses DNA synthesis ${ }^{83}$ In 2014 , a study on human squamous cell oesophageal carcinoma, indicated that diallyl disulphide had the ability to significantly reduce cell viability in a dose- and timedependent manner and diallyl disulphide had been shown to arrest G2/M phase arrest. ${ }^{84}$ In this regard, Yin and colleague have reported that diallyl disulphide had the potential to block the metastasis of oesophageal adenocarcinoma cell lines. ${ }^{85}$ The earlier findings revealed that a diallyl disulfide induces human leukaemia cell differentiation, and proteomic analysis advocated that calreticulin was involved in diallyl disulfide facilitated induction of differentiation in cancer cells. ${ }^{86-87}$ The antiproliferative effect of allicin on ovarian cancer cells was evaluated by treating the cells to various concentrations of allicin. The result showed that cell growth was inhibited in a dose- and time-dependent manner. Moreover, cancer cells exhibited inhibition of proliferation in human ovarian cancer SKOV3 cells in the presence of allicin. ${ }^{88} \mathrm{~A}$ study based on allicin reported that allicin inhibited proliferation of gastric carcinoma cells via decreasing the cell viability. Moreover, the level of apoptosis was modulated through reactive oxygen species generation and a decrease in mitochondrial membrane potential mediated. ${ }^{89}$ Another study based on renal clear cell carcinoma progression was

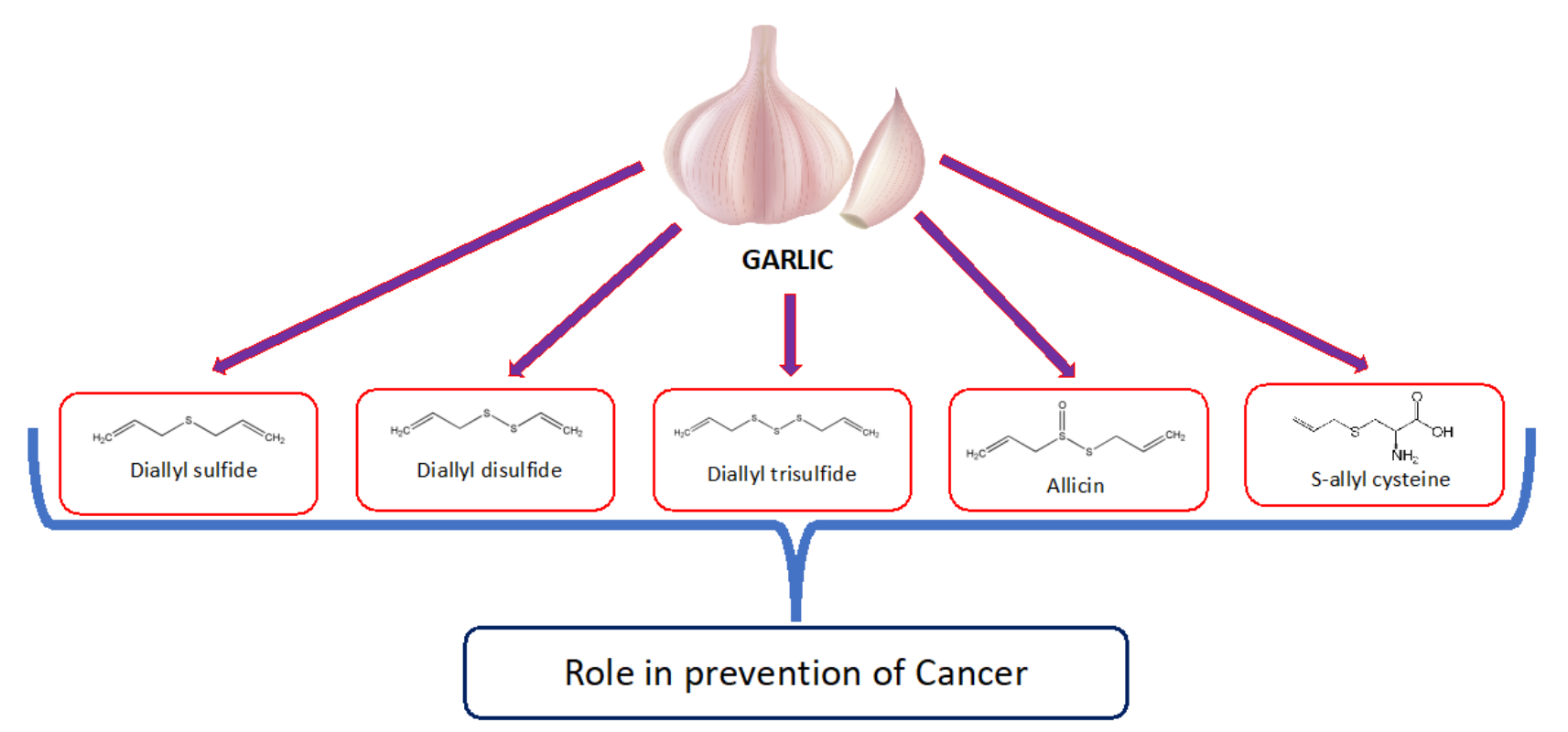

Figure 3: Garlic and its active compounds role in cancer management. 
performed by Song and colleagues and it was reported that treatment with allicin significantly decreased Hypoxia-inducible factor 1-alpha protein level, thus decreasing Bcl-2 and vascular endothelial growth factor expression and allicin also clearly enhanced apoptotic cells. ${ }^{91}$ It was further suggested that the antitumor activity of allicin in gastric carcinoma, breast cancer, and glioblastoma chiefly occurs through inhibition of cell proliferation and induction of cell apoptosis. ${ }^{91,92}$ Sun and colleagues examined the role of allicin on telomerase activity and apoptosis in gastric cancer cells. It was seen that apoptosis of the cells was induced by allicin in a dose-dependent manner. Besides, allicin was reported to increase the proportion of cells in the $\mathrm{G}_{2} / \mathrm{M}$ phase. Allicin inhibited telomerase activity in a time-dependent and dose-dependent pattern. ${ }^{93}$ Moreover, several previous studies provided evidence that garlic-based nano-formulation has the potential to kill the cancer cells.

\section{Neuroprotective effect}

Antioxidant and anti-inflammatory potentials of several natural products or active compounds of herbs are considered to be responsible for their neuroprotection activity. It has been suggested that significant antioxidant activity of curcumin, thymoquinone and ginger play a chief role in their ability to offer neuroprotection. Nillert et al. (2017) have reported that short-term recognition memory in cognitively impaired rats becomes significantly improved by garlic extract. In addition, the inflammatory response extract was considerably decreased. Thus, aged garlic extract may be helpful against cognitive dysfunction and neuroinflammation induced by beta-amyloid in rats. ${ }^{94}$ Effects of garlic extract on cognitive dysfunction in beta-induced rats were examined. Findings showed that extract had significant potential in the improvement of the working memory and reduction in loss of cholinergic neurons. ${ }^{95}$ In 2104 , neuroprotective effects of allicin against traumatic brain injury were investigated. It was reported that treatment by allicin considerably reduced brain edema. ${ }^{96}$ Neuroprotection offered by allicin may be suggested to be associated with the improvement of mitochondrial function ${ }^{97}$ and allicin treatment could be a potential therapeutic approach for traumatic neuronal injury. ${ }^{98}$ The effect of allicin in cerebral ischemia/reperfusion injury was checked and it was reported that allicin reduced cerebral infarction area and neuronal apoptosis. ${ }^{99}$ Another study concluded that the effects of allicin on traumatic spinal cord injury were mediated via regulation of the Akt and iNOS pathways ${ }^{100}$ and hearing loss could be prevented by allicin. ${ }^{101}$ The effects of Mielyn oligodendrocyte glycoprotein have been reported to be decreased by the administration of S-allyl cysteine ${ }^{88}$ Another finding suggests that $S$-allyl cysteine has been considerably associated with its neuroprotective effects against experimental stroke. ${ }^{103}$

\section{Photoprotective effect}

Photo-protection is the process that provides the defence to an organism against cellular and molecular changes caused by sunlight. Several plants and active compounds of herbs have been reported to inhibit the effects of sunlight effects and thus, they act as photoprotective agents. The protective effect of garlic on ultraviolet-induced photo-aging and matrix metalloproteinases regulation have been investigated. Findings demonstrated that chronic ultra violet irradiation induced rough wrinkling of the skin, and administration of garlic had been beneficial against the formation of the coarse wrinkle. Moreover, ultravioletinduced dorsal skin and epidermal thickness were also reported to be enhanced by garlic supplementation. ${ }^{104}$

\section{Immunomodulatory effect}

Several researchers have investigated the effects of garlic extract on immune functions. It has been documented that antigen-specific ear swelling becomes significantly inhibited by the extract. ${ }^{105}$ Jafri and colleagues examined the effect of garlic powder on the humoral immune response. It was reported that enhancing broilers with garlic did not show any beneficial effects on antibody production ${ }^{106}$ and injections of the garlic extract showed a significant decrease in the promise criteria of allergic airway inflammation levels. ${ }^{107}$ In 2011, Chandrashekar and colleagues investigated the biological activity of fructans of aged garlic extract. The result confirmed that fructans had mitogenic activity and the ability for activation of macrophages. ${ }^{108}$ Another study data advocate that protein fractions isolated from fresh garlic bulbs enhance CD8 (+) T-cell infiltration into the tumor site and also play a role in the inhibition of tumor growth. ${ }^{109}$ Moreover, another study result showed that garlic oil enhanced the lymphocyte proliferation rate accompanied via an elevated production of cytokines. ${ }^{110}$

\section{Role in nephrotoxicity}

The potent antioxidant and anti-inflammatory properties of natural products such as curcumin, thymoquinone and ginger extract have been established to be responsible for their anti-nephrotoxicity effects. A study on protective effects of aged garlic extract on nephrotoxicity had reported that garlic extract treatment meaningfully protected animals against Cyclosporin A -induced biochemical changes. Further, the pre-treatment of rats with garlic extract considerably improved the histopathological changes in their kidney. ${ }^{111}$ Nasri and coworkers have successfully evaluated the effects of a garlic preparation on nephrotoxicity. The findings have indicated that damage score becomes considerably reduced by post administration of garlic after gentamicin treatment or co-administration of garlic and gentamicin considerably. Thus, the results suggest the nephron-protective effect of the garlic extract. ${ }^{12}$ In 2003, an investigation based on garlic extract has reported that an increase in the renal levels of oxidative stress markers and the decrease in manganese superoxide dismutase and glutathione reductase activities becomes prevented by the extract. The protective effect of garlic extract was related to the decrease in the oxidative stress and the preservation of manganese superoxide dismutase and glutathione reductase activities in the renal cortex. ${ }^{113}$ Another study result concluded that both allicin and ascorbic acids showed substantial nephro-protective effects against cisplatin intoxication and their combination exhibited better protection than either agent alone. ${ }^{114}$

\section{Reproductive system}

A male reproduction system is a group of an organ such as testes, epididymis, vas deferens and linked hormones and proper functioning of the organ is important for the male reproductive system. In traditional medicine such as Unani, Ayurveda and Chinese, preparations based on plant source has confirmed a significant role of herbs and their ingredients in maintaining the health of the reproductive system. The effect of chronic consumption of garlic was evaluated on reproductive functions. The seminiferous tubules of rats treated with garlic showed an increased number of tubules depressed of spermatozoa. In addition, garlic fractions also play a role in the induction of apoptosis of testicular germ cells and play a role in the decrease of serum testosterone levels. ${ }^{115}$ Moreover, it was reported that treatment with vitamin $\mathrm{E}$ and aqueous garlic extract resulted in a significant increase in sperm motility and viability. ${ }^{116}$

\section{Antithrombotic activities}

Many researchers have examined the antithrombotic activities of garlic powder. Based on the study conducted by Fukao and colleagues, garlic was documented both to activate fibrinolytic activity via increased t-PAmediated plasminogen activation as well as to suppress the coagulation system by decreasing thrombin formation. ${ }^{117}$ Previous studies reported that extracts such as onion, garlic and ginger had the ability to inhibit platelet aggregation induced by various aggregation agents. ${ }^{118}$ Moreover, it was reported that garlic oil complement meaningfully elongated bleeding time and thrombin time, and showed a role in the improvement of anticoagulation factor activity. In addition, the study 
revealed that the anticoagulant action of garlic oil was attributed to its potential to inhibit thrombin. ${ }^{119}$ In a study, administration of the garlic to thirty patients with coronary artery disease was done. Whereas, another thirty patients received the placebo. The finding reported that diallyl disulphide and diallyl trisulphide showed antiplatelet activity and decreased platelet thromboxane formation. ${ }^{120}$

\section{Radio-sensitization}

A radiosensitizer is a material that holds the potential to make tumor cells sensitive to radiation therapy and finally play a role in the tumour growth inhibition. The radio-sensitization effect of black garlic extract on lung cancer cell lines has been checked. The result revealed that mixture of extract and radiotherapy considerably induced apoptosis in the G2/M stage clearly decreased the expression of bcl-2 and increased the expression of Bax. ${ }^{121}$

\section{Effect of Garlic and its active compound alone and in combination with other anti-cancer compounds}

Natural compound including garlic has proven chemopreventive role through modulating various biological activities. ${ }^{122-130}$ Doxorubicin, cisplatin, and 5-fluorouracil, are popular anti-cancer drugs used in the treatment of cancer. Moreover, laboratories experiment evidence that doxorubicin, cisplatin and 5-fluorouracil had anti-cancerous activity due to their ability to kill cancer cells but they had been linked with several adverse effects. An experiment has provided the evidences that the administration of both aged garlic extract and naltrexone, together showed significantly longer survival time as compared with the mice treated with aged garlic extract or Naltrexone alone. Moreover, improved inhibitory effect on tumor growth was observed in the combination therapy group and combination therapy showed improvement of immune responses against experimentally implanted fibrosarcoma tumors. ${ }^{131}$ Diallyl trisulfide has been reported to sensitize gastric cancer cells to docetaxel, and to enhance G2/M phase cell cycle arrest and apoptosis. Besides, a combination of diallyl trisulfide with docetaxel showed a synergistic anti-GC activity conveyed by both up-regulation of metallothionein $2 \mathrm{~A}$ as well as inactivation of NF- $\kappa \mathrm{B}$. Histopathologic analysis of GC specimens from patients have shown a significant increase in metallothionein $2 \mathrm{~A}$ expression followed by docetaxel treatment. ${ }^{132}$ Another study in xenograft mice, reported that the administration of diallyl trisulfide inhibited tumor growth in a dose-dependent manner and significantly reduced the number of $\mathrm{Ki}-67$ positive cells in tumors. Remarkably, the combination therapy administration of diallyl trisulfide with DDP showed improved antitumor activity. ${ }^{133}$ Another interesting study reported that diallyl trisulfide in combination with cisplatin showed enhanced anti-tumor activity through induction of apoptosis. Interestedly, diallyl trisulfide in combination with cisplatin administration caused fewer side effects such as suppressing the weight loss and ameliorating cisplatin-induced oxidative injury, particularly in renal parenchyma. Besides, increased E-cadherin and decreased MMP-9 expression levels were observed in diallyl trisulfide -treated tumor tissues. ${ }^{134}$

\section{Strategies to overcome the low bioavailability of garlic and its compound}

Poor absorption, rapid metabolism, and rapid elimination of garlic compounds are considerable difficulties for bioavailability of a natural product. It is noteworthy that S-allylcysteine can be detected in the plasma, liver and kidney after oral intake. ${ }^{135}$ Previous studies have documented that the bioavailability of S-allylcysteine was $103.0 \%$ in mice, $98.2 \%$ in rats and $87.2 \%$ in dogs. ${ }^{136}$ Allicin is supposed to be the chief compound of garlic and Allicin cannot be detected in the blood or urine after the ingestion of raw garlic or pure allicin within 1 to 24 hours after ingestion of $25 \mathrm{~g}$ raw garlic. ${ }^{137}$ Poor bioavailability of garlic and its compound can be overcome through nanoformulations and such preparation have been suggested to improve the bioavailability, and to reduce the toxicity. The chemo-preventive effects of liposomized DAS against DMBA-induced skin papilloma were evaluated. The result demonstrated that liposomized DAS efficiently hindered the beginning of tumorogenesis and reduced the cumulative numbers and sizes of tumor papilloma in treated mice. Treatment of DMBA-exposed animals with the liposomal formulation of DAS resulted in p53wt and p21/Waf1, although levels of p53mut expression reduced down. ${ }^{138}$ Another study result exhibited that Niosomal diallyl sulfide (12 mg/kg body weight) meaningfully reduced fungal load and mortality in treated animals as compared with the free form of diallyl sulfide. Moreover, niosomal diallyl sulfide was also found to be free of toxic appearances, as shown by histopathological analysis and liver/kidney function tests. ${ }^{139}$

\section{CONCLUSION}

Garlic has been used as a spice in daily life since ancient time and its disease cure potentiality has been documented. The garlic contains various bioactive compounds that account for the disease cure through modulating various biological cascades. Besides, antioxidants of garlic extract can scavenge various free radicals and thus, can be helpful against damage of cell membranes and various biomolecules including DNA. This review may be beneficial in improving our information about the therapeutic potential of garlic and expanding our future experimental and clinical research strategies. The therapeutic role of chemical constituents of garlic has been investigated through various studies based on in vivo and in vitro studies and evidence advocate that garlic ingredients have anti-cancer, anti-diabetic, antioxidant, neuroprotective, cardio-preventive, immunomodulatory, photoprotective effects. Various strategies (niosomal, nanoformulations, liposomal strategy, etc) overcome the problem of bioavailability, absorption, metabolism and elimination of active ingredients of garlic. Apart from the combined use of active ingredients of garlic with drugs (combinational therapies), more effort should be put on the conventional drugs in combination with new formulations/strategies in order to improve the therapeutic efficacy of drugs, reducing toxicity and side effects. Focus on such strategies may be helpful to overcome the major obstacles (such as toxicity, side effects, resistance to drugs/ therapies, specificity, availability, delivery) at the clinical level in the future. However, further studies based on clinical trial and animal model are needed to explore its role and effectiveness in diseases cure without any adverse effect. Besides, long-term trials of different doses and time durations are needed to investigate the possible side effects of garlic extract.

\section{REFERENCES}

1. Tsai, C. Y. Wang, C. C. Lai, T. Y Tsu, H. N. Wang C. H. Liang, H. Y \& Kuo, W. W. (2013). Antioxidant effects of diallyl trisulfide on high glucose-induced apoptosis are mediated by the PI3K/Akt-dependent activation of Nrf2 in cardiomyocytes. International journal of cardiology, 168(2), 1286-1297.

2. Dhuley, J. N., Naik, S. R., Rele, S., \& Banerji, A. (1999). Hypolipidaemic and antioxidant activity of diallyl disulphide in rats. Pharmacy and Pharmacology Communications, 5(12), 689-696.

3. Hodge, G., Hodge, S., \& Han, P. (2002). Allium sativum (garlic) suppresses leukocyte inflammatory cytokine production in vitro: potential therapeutic use in the treatment of inflammatory bowel disease. Cytometry: The Journal of the International Society for Analytical Cytology, 48(4), 209-215.

4. Quintero-Fabián, S., Ortuño-Sahagún, D., Vázquez-Carrera, M., \& López-Roa, R. I. (2013). Alliin, a garlic (Allium sativum) compound, prevents LPS-induced inflammation in 3T3-L1 adipocytes. Mediators of inflammation, 2013.

5. Oommen, S., Anto, R. J., Srinivas, G., \& Karunagaran, D. (2004). Allicin (from garlic) induces caspase-mediated apoptosis in cancer cells. European journal of pharmacology, 485(1-3), 97-103

6. Dirsch, V. M., Gerbes, A. L., \& Vollmar, A. M. (1998). Ajoene, a compound of garlic, induces apoptosis in human promyeloleukemic cells, accompanied by generation of reactive oxygen species and activation of nuclear factor $\mathrm{QB}$. Molecular pharmacology, 53(3), 402-407. 
7. Morihara, N., Hayama, M., \& Fujii, H. (2011). Aged garlic extract scavenges superoxide radicals. Plant Foods for Human Nutrition, 66(1), 17-21.

8. Benkeblia, N. (2005). Free-radical scavenging capacity and antioxidant properties of some selected onions (Allium cepa L.) and garlic (Allium sativum L.) extracts. Brazilian archives of biology and technology, 48(5), 753-759.

9. Park, J. H., Park, Y. K., \& Park, E. (2009). Antioxidative and antigenotoxic effects of garlic (Allium sativum L.) prepared by different processing methods. Plant foods for human nutrition, 64(4), 244.

10. Tanaka, S., Haruma, K., Yoshihara, M., Kajiyama, G., Kira, K., Amagase, H., \& Chayama, K. (2006). Aged garlic extract has potential suppressive effect on colorectal adenomas in humans. The Journal of nutrition, 136(3), 821S-826S.

11. Huang, C. H., Hsu, F. Y., Wu, Y. H., Zhong, L., Tseng, M. Y., Kuo, C. J., ... \& Chiou, S. H. (2015). Analysis of lifespan-promoting effect of garlic extract by an integrated metabolo-proteomics approach. The Journal of nutritional biochemistry, 26(8), 808-817.

12. Hodge, G., Hodge, S., \& Han, P. (2002). Allium sativum (garlic) suppresses leukocyte inflammatory cytokine production in vitro: potential therapeutic use in the treatment of inflammatory bowel disease. Cytometry: The Journal of the International Society for Analytical Cytology, 48(4), 209-215.

13. Youn, H. S., Lim, H. J., Lee, H. J., Hwang, D., Yang, M., Jeon, R., \& Ryu, J. H. (2008). Garlic (Allium sativum) extract inhibits lipopolysaccharide-induced Toll-like receptor 4 dimerization. Bioscience, biotechnology, and biochemistry, 72(2), 368-375.

14. Puccinelli, M. T., \& Stan, S. D. (2017). Dietary bioactive diallyl trisulfide in cancer prevention and treatment. International journal of molecular sciences, 18(8), 1645.

15. Huang, J., Yang, B., Xiang, T., Peng, W., Qiu, Z., Wan, J., ... \& Ren, G. (2015). Diallyl disulfide inhibits growth and metastatic potential of human triplenegative breast cancer cells through inactivation of the $\beta$-catenin signaling pathway. Molecular nutrition \& food research, 59(6), 1063-1075.

16. Wallace, G. C., Haar, C. P., Vandergrift, W. A., Giglio, P., Dixon-Mah, Y. N., Varma, A. K., ... \& Das, A. (2013). Multi-targeted DATS prevents tumor progression and promotes apoptosis in ectopic glioblastoma xenografts in SCID mice via HDAC inhibition. Journal of neuro-oncology, 114(1), 43-50.

17. Jiang, X., Zhu, X., Huang, W., Xu, H., Zhao, Z., Li, S., ... \& Cao, J. (2017). Garlicderived organosulfur compound exerts antitumor efficacy via activation of MAPK pathway and modulation of cytokines in SGC-7901 tumor-bearing mice. International immunopharmacology, 48, 135-145.

18. Milner, J. A. (2001). Mechanisms by which garlic and allyl sulfur compounds suppress carcinogen bioactivation. In Nutrition and Cancer Prevention (pp. 6981). Springer, Boston, MA.

19. Ankri, S., \& Mirelman, D. (1999). Antimicrobial properties of allicin from garlic. Microbes and infection, 1(2), 125-129.

20. Fujisawa, H., Watanabe, K., Suma, K., Origuchi, K., Matsufuji, H., Seki, T., \& Ariga, T. (2009). Antibacterial potential of garlic-derived allicin and its cancellation by sulfhydryl compounds. Bioscience, biotechnology, and biochemistry, 73(9), 1948-1955

21. Focke, M., Feld, A., \& Lichtenthaler, H. K. (1990). Allicin, a naturally occurring antibiotic from garlic, specifically inhibits acetyl-CoA synthetase. FEBS letters, 261(1), 106-108.

22. Chung, L. Y. (2006). The antioxidant properties of garlic compounds: ally cysteine, alliin, allicin, and allyl disulfide. Journal of medicinal food, 9(2), 205213.

23. Jang, H. J., Lee, H. J., Yoon, D. K., Ji, D. S., Kim, J. H., \& Lee, C. H. (2018). Antioxidant and antimicrobial activities of fresh garlic and aged garlic byproducts extracted with different solvents. Food science and biotechnology, $27(1), 219-225$

24. Prasad, K., Laxdal, V. A., Yu, M., \& Raney, B. L. (1995). Antioxidant activity of allicin, an active principle in garlic. Molecular and Cellular Biochemistry, 148(2), 183-189.

25. Kay, H. Y., Won Yang, J., Kim, T. H., Lee, D. Y., Kang, B., Ryu, J. H., ... \& Kim, S. G. (2010). Ajoene, a stable garlic by-product, has an antioxidant effect through Nrf2-mediated glutamate-cysteine ligase induction in HepG2 cells and primary hepatocytes. The Journal of nutrition, 140(7), 1211-1219.

26. Franco-Enzástiga, Ú., Santana-Martínez, R. A., Silva-Islas, C. A., Barrera-Oviedo, D., Chánez-Cárdenas, M. E., \& Maldonado, P. D. (2017). Chronic administration of S-allylcysteine activates Nrf2 factor and enhances the activity of antioxidant enzymes in the striatum, frontal cortex and hippocampus. Neurochemical research, 42(11), 3041-3051.

27. Kalayarasan, S., Prabhu, P. N., Sriram, N., Manikandan, R., Arumugam, M., \& Sudhandiran, G. (2009). Diallyl sulfide enhances antioxidants and inhibits inflammation through the activation of Nrf2 against gentamicin-induced nephrotoxicity in Wistar rats. European journal of pharmacology, 606(1-3), 162171.

28. Lee, D. Y., Li, H., Lim, H. J., Lee, H. J., Jeon, R., \& Ryu, J. H. (2012). Antiinflammatory activity of sulfur-containing compounds from garlic. Journal of medicinal food, 15(11), 992-999.
29. Badr, G. M., \& AL-Mulhim, J. A. (2014). The protective effect of aged garlic extract on nonsteroidal anti-inflammatory drug-induced gastric inflammations in male albino rats. Evidence-Based Complementary and Alternative Medicine, 2014.

30. Kim, S. R., Jung, Y. R., An, H. J., Kim, D. H., Jang, E. J., Choi, Y. J., ... \& Bae, H. R. (2013). Anti-wrinkle and anti-inflammatory effects of active garlic components and the inhibition of MMPs via NF-kB signaling. PloS one, 8(9).

31. Shin, J. H., Ryu, J. H., Kang, M. J., Hwang, C. R., Han, J., \& Kang, D. (2013). Short-term heating reduces the anti-inflammatory effects of fresh raw garlic extracts on the LPS-induced production of NO and pro-inflammatory cytokines by downregulating allicin activity in RAW 264.7 macrophages. Food and chemical toxicology, 58, 545-551.

32. Pandurangan, A. K., Ismail, S., Saadatdoust, Z., \& Esa, N. M. (2015). Allicin alleviates dextran sodium sulfate-(DSS-) induced ulcerative colitis in BALB/C mice. Oxidative medicine and cellular longevity, 2015

33. Hall, A., Troupin, A., Londono-Renteria, B., \& Colpitts, T. M. (2017). Garlic organosulfur compounds reduce inflammation and oxidative stress during dengue virus infection. Viruses, 9(7), 159.

34. Keiss, H. P., Dirsch, V. M., Hartung, T., Haffner, T., Trueman, L., Auger, J., ... \& Vollmar, A. M. (2003). Garlic (Allium sativum L.) modulates cytokine expression in lipopolysaccharide-activated human blood thereby inhibiting NF-kB activity. The Journal of nutrition, 133(7), 2171-2175

35. Eidi, A., Eidi, M., \& Esmaeili, E. (2006). Antidiabetic effect of garlic (Allium sativum L.) in normal and streptozotocin-induced diabetic rats. Phytomedicine, 13(9-10), 624-629.

36. Liu, C. T., Hsu, T. W., Chen, K. M., Tan, Y. P., Lii, C. K., \& Sheen, L. Y. (2012). The antidiabetic effect of garlic oil is associated with ameliorated oxidative stress but not ameliorated level of pro-inflammatory cytokines in skeletal muscle of streptozotocin-induced diabetic rats. Journal of traditional and complementary medicine, 2(2), 135-144.

37. Thomson, M., Al-Qattan, K. K., Divya, J. S., \& Ali, M. (2015). Anti-diabetic and anti-oxidant potential of aged garlic extract (AGE) in streptozotocin-induced diabetic rats. BMC Complementary and Alternative Medicine, 16(1), 17.

38. Thomson, M., Al-Amin, Z. M., Al-Qattan, K. K., Shaban, L. H., \& Ali, M. (2007). Anti-diabetic and hypolipidaemic properties of garlic (Allium sativum) in streptozotocin-induced diabetic rats. Int J Diabetes \& Metabolism, 15, 108-115.

39. Padiya, R., Khatua, T. N., Bagul, P. K., Kuncha, M., \& Banerjee, S. K. (2011). Garlic improves insulin sensitivity and associated metabolic syndromes in fructose fed rats. Nutrition \& metabolism, 8(1), 53.

40. Bokaeian, M., Nakhaee, A., Moodi, B., Farhangi, A., \& Akbarzadeh, A. (2010). Effects of garlic extract treatment in normal and streptozotocin diabetic rats infected with Candida albicans. Indian Journal of clinical biochemistry, 25(2), 182-187.

41. Liu, C. T., Wong, P. L., Lii, C. K., Hse, H., \& Sheen, L. Y. (2006). Antidiabetic effect of garlic oil but not diallyl disulfide in rats with streptozotocin-induced diabetes. Food and chemical toxicology, 44(8), 1377-1384.

42. Liu, C. T., Hse, H., Lii, C. K., Chen, P. S., \& Sheen, L. Y. (2005). Effects of garlic oil and diallyl trisulfide on glycemic control in diabetic rats. European journal of pharmacology, 516(2), 165-173.

43. Zhai, B., Zhang, C., Sheng, Y., Zhao, C., He, X., Xu, W., ... \& Luo, Y. (2018). Hypoglycemic and hypolipidemic effect of S-allyl-cysteine sulfoxide (alliin) in DIO mice. Scientific reports, 8(1), 1-7.

44. Sheela, C. G., \& Augusti, K. T. (1992). Antidiabetic effects of S-allyl cysteine sulphoxide isolated from garlic Allium sativum Linn. Indian journal of experimental biology, 30(6), 523-526.

45. El-Ashmawy, N. E., Khedr, E. G., El-Bahrawy, H. A., \& Selim, H. M. (2016), Gastroprotective effect of garlic in indomethacin induced gastric ulcer in rats. Nutrition, 32(7-8), 849-854.

46. Badr. G.M., Al-Mulhim, J.A. The protective effect of aged garlic extract on nonsteroidal anti-inflammatory drug-induced gastric inflammations in male albino rats, Evid Based Complement Alternat. Med. 2014 (2014) 759642.

47. Lee, H. S., Lim, W. C., Lee, S. J., Lee, S. H., Yu, H. J., Lee, J. H., \& Cho, H. Y. (2016). Hepatoprotective effects of lactic acid-fermented garlic extract against acetaminophen-induced acute liver injury in rats. Food science and biotechnology, 25(3), 867-873.

48. Shin, J. H., Lee, C. W., Oh, S. J., Yun, J., Kang, M. R., Han, S. B., ... \& Kang, J. S. (2014). Hepatoprotective effect of aged black garlic extract in rodents. Toxicological research, 30(1), 49-54.

49. Naji, K. M., Al-Shaibani, E. S., Alhadi, F. A., \& D'souza, M. R. (2017). Hepatoprotective and antioxidant effects of single clove garlic against CC 4 -induced hepatic damage in rabbits. BMC complementary and alternative medicine, 17(1), 411.

50. Vimal, V., \& Devaki, T. (2004). Hepatoprotective effect of allicin on tissue defense system in galactosamine/endotoxin challenged rats. Journal of ethnopharmacology, 90(1), 151-154. 
51. Anandasadagopan, S. K., Sundaramoorthy, C., Pandurangan, A. K., Nagarajan, V., Srinivasan, K., \& Ganapasam, S. (2017). S-Allyl cysteine alleviates inflammation by modulating the expression of NF-KB during chromium (VI)induced hepatotoxicity in rats. Human \& experimental toxicology, 36(11), 11861200.

52. Park, J. M., Han, Y. M., Kangwan, N., Lee, S. Y., Jung, M. K., Kim, E. H., \& Hahm, K. B. (2014). S-allyl cysteine alleviates nonsteroidal anti-inflammatory drug-induced gastric mucosal damages by increasing cyclooxygenase-2 inhibition, heme oxygenase-1 induction, and histone deacetylation inhibition. Journal of gastroenterology and hepatology, 29, 80-92.

53. Sumedha, N. C., \& Miltonprabu, S. (2015). Diallyl trisulfide ameliorates arsenicinduced hepatotoxicity by abrogation of oxidative stress, inflammation, and apoptosis in rats. Human \& experimental toxicology, 34(5), 506-525.

54. Wu, C. C., Sheen, L. Y., Chen, H. W., Kuo, W. W., Tsai, S. J., \& Lii, C. K. (2002). Differential effects of garlic oil and its three major organosulfur components on the hepatic detoxification system in rats. Journal of agricultural and food chemistry, 50(2), 378-383

55. Nejad, A. S. M., Shabani, S., Bayat, M., \& Hosseini, S. E. (2014). Antibacterial effect of garlic aqueous extract on Staphylococcus aureus in hamburger. Jundishapur journal of microbiology, 7(11).

56. Shokrzadeh, M., \& Ebadi, A. G. (2006). Antibacterial effect of garlic (Allium sativum L.) on Staphylococcus aureus. Pak. J. Biol. Sci, 9(8), 1577-9.

57. Velliyagounder, K., Ganeshnarayan, K., Velusamy, S. K., \& Fine, D. H. (2012). In vitro efficacy of diallyl sulfides against the periodontopathogen Aggregatibacter actinomycetemcomitans. Antimicrobial agents and chemotherapy, 56(5), 23972407.

58. Chung, J. G., Chen, G. W., Wu, L. T., Chang, H. L., Lin, J. G., Yeh, C. C., \& Wang, T. F. (1998). Effects of garlic compounds diallyl sulfide and diallyl disulfide on arylamine $\mathrm{N}$-acetyltransferase activity in strains of Helicobacter pylori from peptic ulcer patients. The American journal of Chinese medicine, 26(03n04), 353-364

59. Alam, M., Dwivedi, V., Khan, A. A., \& Mohammad, O. (2009). Efficacy of niosomal formulation of diallyl sulfide against experimental candidiasis in Swiss albino mice. Nanomedicine, 4(7), 713-724.

60. Aala, F., Yusuf, U. K., Nulit, R., \& Rezaie, S. (2014). Inhibitory effect of allicin and garlic extracts on growth of cultured hyphae. Iranian journal of basic medical sciences, 17(3), 150.

61. Lemar, K. M., Aon, M. A., Cortassa, S., O'Rourke, B., Müller, C. T., \& Lloyd, D. (2007). Diallyl disulphide depletes glutathione in Candida albicans: oxidative stress-mediated cell death studied by two-photon microscopy. Yeast, 24(8), 695-706.

62. Yousuf, S., Ahmad, A., Khan, A., Manzoor, N., \& Khan, L. A. (2010). Effect of diallyldisulphide on an antioxidant enzyme system in Candida species. Canadian journal of microbiology, 56(10), 816-821.

63. Tsao, S. M., Liu, W. H., \& Yin, M. C. (2007). Two diallyl sulphides derived from garlic inhibit meticillin-resistant Staphylococcus aureus infection in diabetic mice. Journal of medical microbiology, 56(6), 803-808.

64. Lu, X., Samuelson, D. R., Rasco, B. A., \& Konkel, M. E. (2012). Antimicrobial effect of diallyl sulphide on Campylobacter jejuni biofilms. Journal of antimicrobial chemotherapy, 67(8), 1915-1926.

65. Mahmoodi, M., Islami, M. R., Asadi, G. K., Khaksari, M., Sahebghadam, A. L., Hajizadeh, M. R., \& Mirzaee, M. R. (2006). Study of the effects of raw garlic consumption on the level of lipids and other blood biochemical factors in hyperlipidemic individuals. Pakistan journal of pharmaceutical sciences, 19(4), 295-298

66. Ali, M., \& Thomson, M. (1995). Consumption of a garlic clove a day could be beneficial in preventing thrombosis. Prostaglandins, leukotrienes and essential fatty acids, 53(3), 211-212

67. Steiner, M., Khan, A. H., Holbert, D., \& Lin, R. I. (1996). A double-blind crossover study in moderately hypercholesterolemic men that compared the effect of aged garlic extract and placebo administration on blood lipids. The American journal of clinical nutrition, 64(6), 866-870.

68. Luley, C., Lehmann-Leo, W., Möller, B., Martin, T., \& Schwartzkopff, W. (1986). Lack of efficacy of dried garlic in patients with hyperlipoproteinemia. Arzneimittel-Forschung, 36(4), 766-768.

69. Mader, F. H. (1990). Treatment of hyperlipidaemia with garlic-powder tablets. Evidence from the German Association of General Practitioners' multicentric placebo-controlled double-blind study. Arzneimittel-Forschung, 40(10), 11111116.

70. Bakhsh, R., \& Chughtai, M. I. D. (1984). Influence of garlic on serum cholesterol, serum triglycerides, serum total lipids and serum glucose in human subjects. Food/Nahrung, 28(2), 159-163.

71. García-Trejo, E., Arellano-Buendía, A. S., Argüello-García, R., Loredo-Mendoza, M. L., García-Arroyo, F. E., Arellano-Mendoza, M. G., ... \& Osorio-Alonso, H. (2016). Effects of allicin on hypertension and cardiac function in chronic kidney disease. Oxidative medicine and cellular longevity, 2016.
72. Shackebaei, D., Ghazvineh, S., Godini, A., Pilehvarian, A., Reshadat, S. (2010) Cardioprotective effect of garlic juice on the isolated rat heart in ischemiareperfusion, J. Med. Plants. (71-79), (35)5.

73. Ried, K. (2016). Garlic lowers blood pressure in hypertensive individuals, regulates serum cholesterol, and stimulates immunity: an updated metaanalysis and review. The Journal of nutrition, 146(2), 389S-396S.

74. Rashid, A., \& Khan, H. H. (1985). The mechanism of hypotensive effect of garlic extract. J Pak Med Assoc, 35(12), 357-62.

75. Kamanna, V. S., \& Chandrasekhara, N. (1982). Effect of garlic (Allium sativum Linn) on serum lipoproteins and lipoprotein cholesterol levels in albino rats rendered hypercholesteremic by feeding cholesterol. Lipids, 17(7), 483-488..

76. Ried, K., Frank, O. R., \& Stocks, N. P. (2013). Aged garlic extract reduces blood pressure in hypertensives: a dose-response trial. European Journal of Clinical Nutrition, 67(1), 64-70.

77. Cruz, C., Correa-Rotter, R., Sánchez-González, D. J., Hernández-Pando, R., Maldonado, P. D., Martínez-Martínez, C. M., ... \& Pedraza-Chaverri, J. (2007). Renoprotective and antihypertensive effects of S-allylcysteine in 5/6 nephrectomized rats. American Journal of Physiology-Renal Physiology, 293(5), F1691-F1698.

78. Bae, J., Kumazoe, M., Fujimura, Y., \& Tachibana, H. (2019). Diallyl disulfide potentiates anti-obesity effect of green tea in high-fat/high-sucrose dietinduced obesity. The Journal of nutritional biochemistry, 64, 152-161.

79. Yang, C., Li, L., Yang, L., Lü, H., Wang, S., \& Sun, G. (2018). Anti-obesity and Hypolipidemic effects of garlic oil and onion oil in rats fed a high-fat diet. Nutrition \& metabolism, 15(1), 43.

80. Lee, H. S., Lim, W. C., Lee, S. J., Lee, S. H., Lee, J. H., \& Cho, H. Y. (2016) Antiobesity effect of garlic extract fermented by lactobacillus plantarum bl2 in diet-induced obese mice. Journal of medicinal food, 19(9), 823-829.

81. Zhang, Y., Xu, L., Ding, M., Su, G., \& Zhao, Y. (2019). Anti-obesity effect of garlic oil on obese rats via Shenque point administration. Journal of ethnopharmacology, 231, 486-493.

82. Lee, M. S., Kim, I. H., Kim, C. T., \& Kim, Y. (2011). Reduction of body weight by dietary garlic is associated with an increase in uncoupling protein mRNA expression and activation of AMP-activated protein kinase in diet-induced obese mice. The Journal of nutrition, 141(11), 1947-1953.

83. Altonsy, M. O., Habib, T. N., \& Andrews, S. C. (2012). Diallyl disulfide-induced apoptosis in a breast-cancer cell line (MCF-7) may be caused by inhibition of histone deacetylation. Nutrition and cancer, 64(8), 1251-1260.

84. Yin, X., Zhang, R., Feng, C., Zhang, J., Liu, D., Xu, K., ... \& Ma, H. (2014). Dially disulfide induces $\mathrm{G} 2 / \mathrm{M}$ arrest and promotes apoptosis through the p53/p21 and MEK-ERK pathways in human esophageal squamous cell carcinoma. Oncology reports, 32(4), 1748-1756.

85. Yin, X., Feng, C., Han, L., Ma, Y., Jiao, Y., Wang, J., ... \& Zhang, J. (2018) Diallyl disulfide inhibits the metastasis of type II esophageal-gastric junction adenocarcinoma cells via NF-KB and PI3K/AKT signaling pathways in vitro. Oncology reports, 39(2), 784-794.

86. Yi, L., Shan, J., Chen, X., Li, G., Li, L.,Tan, H., \& Su, O (2016). Involvement of calreticulin in cell proliferation, invasion and differentiation in diallyl disulfidetreated HL-60 cells. Oncology letters, 12(3), 1861-1867.

87. Sun, J., Mu, H., Dai, K., \& Yi, L. (2017). Calreticulin: A potential anti-cancer therapeutic target. Die Pharmazie-An International Journal of Pharmaceutical Sciences, 72(9), 503-510

88. Xu, L., Yu, J., Zhai, D., Zhang, D., Shen, W., Bai, L., ... \& Yu, C. (2014). Role of JNK activation and mitochondrial Bax translocation in allicin-induced apoptosis in human ovarian cancer SKOV3 cells. Evidence-Based Complementary and Alternative Medicine, 2014.

89. Mansingh, D. P., Dalpati, N., Sali, V. K., \& Vasanthi, A. H. R. (2018). Alliin the precursor of allicin in garlic extract mitigates proliferation of gastric adenocarcinoma cells by modulating apoptosis. Pharmacognosy Magazine, 14(55), 84.

90. Song, B., Shu, Y., Cui, T., \& Fu, P. (2015). Allicin inhibits human renal clear cell carcinoma progression via suppressing HIF pathway. International journal of clinical and experimental medicine, 8(11), 20573.

91. Li, S., Chen, S., Yang, W., Liao, L., Li, S., Li, J., ... \& Zhu, D. (2017). Allicin relaxes isolated mesenteric arteries through activation of PKA-KATP channel in rat. Journal of Receptors and Signal Transduction, 37(1), 17-24.

92. Yang, D., Lv, Z., Zhang, H., Liu, B., Jiang, H., Tan, X., ... \& Zhang, Z. (2017) Activation of the Nrf2 signaling pathway involving KLF9 plays a critical role in allicin resisting against arsenic trioxide-induced hepatotoxicity in rats. Biological trace element research, 176(1), 192-200.

93. Sun, L., \& Wang, X. (2003). Effects of allicin on both telomerase activity and apoptosis in gastric cancer SGC-7901 cells. World journal of gastroenterology, 9(9), 1930

94. Nillert, N., Pannangrong, W., Welbat, J. U., Chaijaroonkhanarak, W. Sripanidkulchai, K., \& Sripanidkulchai, B. (2017). Neuroprotective effects of aged garlic extract on cognitive dysfunction and neuroinflammation induced by $\beta$-amyloid in rats. Nutrients, 9(1), 24 
95. Thorajak, P., Pannangrong, W., Welbat, J. U., Chaijaroonkhanarak, W., Sripanidkulchai, K., \& Sripanidkulchai, B. (2017). Effects of aged garlic extract on cholinergic, glutamatergic and GABAergic systems with regard to cognitive impairment in $A \beta$-induced rats. Nutrients, 9(7), 686

96. Chen, W., Qi, J., Feng, F., Bao, G., Wang, T., Xiang, M., \& Xie, W. F. (2014). Neuroprotective effect of allicin against traumatic brain injury via Akt/endothelial nitric oxide synthase pathway-mediated anti-inflammatory and anti-oxidative activities. Neurochemistry international, 68, 28-37.

97. Zhu, J. W., Chen, T., Guan, J., Liu, W. B., \& Liu, J. (2012). Neuroprotective effects of allicin on spinal cord ischemia-reperfusion injury via improvement of mitochondrial function in rabbits. Neurochemistry international, 61 (5), 640-648.

98. Zhou, Y. F., Li, W. T., Han, H. C., Gao, D. K., He, X. S., Li, L., ... \& Fei, Z. (2014). Allicin protects rat cortical neurons against mechanical trauma injury by regulating nitric oxide synthase pathways. Brain research bulletin, 100, 14-21.

99. Zhang, B., Li, F., Zhao, W., Li, J., Li, Q., \& Wang, W. (2015). Protective effects of allicin against ischemic stroke in a rat model of middle cerebral artery occlusion. Molecular medicine reports, 12(3), 3734-3738.

100. Wang, S., \& Ren, D. (2016). Allicin protects traumatic spinal cord injury through regulating the HSP70/Akt/iNOS pathway in mice. Molecular medicine reports, 14(4), 3086-3092.

101. Wu, X., Li, X., Song, Y., Li, H., Bai, X., Liu, W., ... \& Wang, H. (2017). Allicin protects auditory hair cells and spiral ganglion neurons from cisplatin-Induced apoptosis. Neuropharmacology, 116, 429-440.

102. Escribano, B. M., Agüera, E., Aguilar-Luque, M., Luque, E., Feijóo, M., LaTorre, M., ... \& Santamaria, A. (2018). Neuroprotective effect of S-allyl cysteine on an experimental model of multiple sclerosis: antioxidant effects. Journal of Functional Foods, 42, 281-288

103. Shi, H., Jing, X., Wei, X., Perez, R. G., Ren, M., Zhang, X., \& Lou, H. (2015). Sallyl cysteine activates the Nrf2-dependent antioxidant response and protects neurons against ischemic injury in vitro and in vivo. Journal of neurochemistry, 133(2), 298-308.

104. Kim, H. K. (2016). Garlic supplementation ameliorates UV-induced photoaging in hairless mice by regulating antioxidative activity and MMPs expression. Molecules, 21(1), 70

105. Kyo, E., Uda, N., Kasuga, S., \& Itakura, Y. (2001). Immunomodulatory effects of aged garlic extract. The Journal of nutrition, 131(3), 1075S-1079S.

106. Jafari, R. A., Jalali, M. R., Ghorbanpoor, M., \& Saraei, S. M. (2008). Effect of dietary garlic on immune response of broiler chicks to live Newcastle disease vaccine. Pakistan Journal of Biological Sciences, 11(14), 1848.

107. Ahad, Z., Parvaneh, F., Zahra, P., Fatemeh, Z., Mostafa, M., \& Shahram, S. (2008). Purified aged garlic extract modulates allergic airway inflammation in BALB/c mice. Iranian Journal of Allergy, Asthma and Immunology, 133-141.

108. Chandrashekar, P. M., Prashanth, K. V. H., \& Venkatesh, Y. P. (2011). Isolation, structural elucidation and immunomodulatory activity of fructans from aged garlic extract. Phytochemistry, 72(2-3), 255-264.

109. Ebrahimi, M., Hassan, Z. M., Mostafaie, A., Mehrjardi, N. Z., \& Ghazanfari, T. (2013). Purif ied protein fraction of garlic extract modulates cellular immune response against breast transplanted tumors in BALB/C mice model. Cell Journal (Yakhteh), 15(1), 65.

110. Liu, C. T., Su, H. M., Lii, C. K., \& Sheen, L. Y. (2009). Effect of supplementation with garlic oil on activity of Th1 and Th2 lymphocytes from rats. Planta medica, 75(03), 205-210.

111. Wongmekiat, O., \& Thamprasert, K. (2005). Investigating the protective effects of aged garlic extract on cyclosporin-induced nephrotoxicity in rats. Fundamental \& clinical pharmacology, 19(5), 555-562.

112. Nasri, H., Nematbakhsh, M., \& Rafieian-Kopaei, M. (2013). Ethanolic extract of garlic for attenuation of gentamicin-induced nephrotoxicity in Wistar rats. Iranian journal of kidney diseases, 7(5), 376-382.

113. Maldonado, P. D., Barrera, D., Medina-Campos, O. N., Hernández-Pando, R., Ibarra-Rubio, M. E., \& Pedraza-Chaverri, J. (2003). Aged garlic extract attenuates gentamicin induced renal damage and oxidative stress in rats. Life Sciences, 73(20), 2543-2556.

114. Abdel-Daim, M. M., Abushouk, A. I., Donia, T., Alarifi, S., Alkahtani, S., Aleya, L., \& Bungau, S. G. (2019). The nephroprotective effects of allicin and ascorbic acid against cisplatin-induced toxicity in rats. Environmental Science and Pollution Research, 26(13), 13502-13509.

115. Hammami, I., Nahdi, A., Atig, F., Kouidhi, W., Amri, M., Mokni, M., ... \& May, M. E. (2013). Effects of garlic fractions consumption on male reproductive functions. Journal of Medicinal Food, 16(1), 82-87.

116. Asadpour, R., Azari, M., Hejazi, M., Tayefi, H., \& Zaboli, N. (2013). Protective effects of garlic aquous extract (Allium sativum), vitamin $\mathrm{E}$, and $\mathrm{N}$-acetylcysteine on reproductive quality of male rats exposed to lead. In Veterinary research forum: an international quarterly journal (Vol. 4, No. 4, p. 251). Faculty of Veterinary Medicine, Urmia University, Urmia, Iran.

117. Fukao, H., Yoshida, H., Tazawa, Y. I., \& Hada, T. (2007). Antithrombotic effects of odorless garlic powder both in vitro and in vivo. Bioscience, biotechnology, and biochemistry, 0612070194-0612070194.
118. Srivastava, K. C. (1984). Aqueous extracts of onion, garlic and ginger inhibit platelet aggregation and alter arachidonic acid metabolism. Biomedica biochimica acta, 43(8-9), S335-46.

119. Chan, K. C., Yin, M. C., \& Chao, W. J. (2007). Effect of diallyl trisulfide-rich garlic oil on blood coagulation and plasma activity of anticoagulation factors in rats. Food and chemical toxicology, 45(3), 502-507.

120. Bordia, A., Verma, S. K., \& Srivastava, K. C. (1998). Effect of garlic (Allium sativum) on blood lipids, blood sugar, fibrinogen and fibrinolytic activity in patients with coronary artery disease. Prostaglandins, leukotrienes and essential fatty acids, 58(4), 257-263.

121. Yang, G. Q., Wang, D., Wang, Y. S., Wang, Y. Y., \& Yang, K. (2013) Radiosensitization effect of black garlic extract on lung cancer cell line Lewis cells. Zhongguo Zhong xi yi jie he za zhi Zhongguo Zhongxiyi jiehe zazhi= Chinese journal of integrated traditional and Western medicine, 33(8), 10931097.

122. Rahmani AH, Alzohairy MA, Khan MA, Aly SM. Therapeutic Implications of Black Seed and Its Constituent Thymoquinone in the Prevention of Cancer through Inactivation and Activation of Molecular Pathways. Evid Based Complement Alternat Med. 2014;2014:724658.

123. Almatroudi A, Alsahli MA, Alrumaihi F, Allemailem KS, Rahmani AH. Ginger: A Novel Strategy to Battle Cancer through Modulating Cell Signalling Pathways: A Review. Curr Pharm Biotechnol. 2019; 20:5-16.

124. Rahmani AH, Aldebasi YH, Srikar S, Khan AA, Aly SM. Aloe vera: Potentia candidate in health management via modulation of biological activities. Pharmacogn Rev 2015;9:120-6.

125. Rahmani AH, Al Shabrmi FM, Allemailem KS, Aly SM, Khan MA. Implications of green tea and its constituents in the prevention of cancer via the modulation of cell signalling pathway. BioMed Res Int. 2015;2015:925640.

126. Rahmani AH, Alsahli MA, Aly SM.; Khan MA, Aldebasi YH. Role of curcumin in disease prevention and treatment. Adv Biomed Res 2018;7:38.

127. Almatroodi SA, Alsahli MA, Almatroudi A, Rahmani AH. Garlic and its active compounds: a potential candidate in the prevention of cancer by modulating various cell signalling pathways. Anticancer Agents Med Chem. 2019;19(11):1314-24.

128. Rahmani A, Alsahli M, Almatroodi S. Active constituents of pomegranates (Punicagranatum) as potential candidates in the management of health through modulation of biological activities. J Pharmacogn. 2017;9(5):689-95.

129. Almatroodi SA, Alrumaihi F, Alsahli MA, Alhommrani MF, Khan A, Rahmani $\mathrm{AH}$. Curcumin, an Active Constituent of Turmeric Spice: Implication in the Prevention of Lung Injury Induced by Benzo(a) Pyrene (BaP) in Rats. Molecules. 2020;25:724.

130. Almatroodi SA, Alsahli MA, Alharbi HM, Khan AA, Husain Rahmani A. Epigallocatechin-3-Gallate (EGCG), An Active Constituent of Green Tea: Implications in the Prevention of Liver Injury Induced by Diethylnitrosamine (DEN) in Rats. Appl Sci. 2019;4:4821

131. Rahmani AH, Almatroudi A, AlRumaihi F, Khan AA. Pharmacological and therapeutic potential of neem (Azadirachta indica). Pharmacogn Rev. 2018;12:250

132. Ebrahimpour, S., Tabari, M. A., Youssefi, M. R., Aghajanzadeh, H., \& Behzadi, M. Y. (2013). Synergistic effect of aged garlic extract and naltrexone on improving immune responses to experimentally induced fibrosarcoma tumor in BALB/c mice. Pharmacognosy research, 5(3), 189.

133. Pan, Y., Lin, S., Xing, R., Zhu, M., Lin, B., Cui, J., ... \& Guo, M. (2016) Epigenetic upregulation of metallothionein $2 \mathrm{~A}$ by diallyl trisulfide enhances chemosensitivity of human gastric cancer cells to docetaxel through attenuating NF-אB activation. Antioxidants \& redox signaling, 24(15), 839-854.

134. Jiang, X. Y., Zhu, X. S., Xu, H. Y., Zhao, Z. X., Li, S. Y., Li, S. Z., ... \& Cao, J. M. (2017). Diallyl trisulfide suppresses tumor growth through the attenuation of Nrf2/Akt and activation of p38/JNK and potentiates cisplatin efficacy in gastric cancer treatment. Acta pharmacologica Sinica, 38(7), 1048-1058.

135. Jiang, X., Zhu, X., Liu, N., Xu, H., Zhao, Z., Li, S., ... \& Cao, J. (2017). Diallyl trisulfide inhibits growth of $\mathrm{NCl}-\mathrm{H} 460$ in vitro and in vivo, and ameliorates cisplatin-induced oxidative injury in the treatment of lung carcinoma in xenograft mice. International journal of biological sciences, 13(2), 167.

136. Nagae, S., Ushijima, M., Hatono, S., Imai, J., Kasuga, S., Matsuura, H., ... \& Higashi, Y. (1994). Pharmacokinetics of the garlic compound S-allylcysteine. Planta medica, 60(03), 214-217.

137. Lawson, L. D., Ransom, D. K., \& Hughes, B. G. (1992). Inhibition of whole blood platelet-aggregation by compounds in garlic clove extracts and commercial garlic products. Thrombosis research, 65(2), 141-156.

138. Khan, A., Shukla, Y., Kalra, N., Alam, M., Ahmad, M. G., Hakim, S. R., \& Owais, M. (2007, July). Potential of diallyl sulfide bearing $\mathrm{pH}$-sensitive liposomes in chemoprevention against DMBA-induced skin papilloma. In Molecular Medicine (Vol. 13, No. 7-8, pp. 443-451). BioMed Central.

139. Alam, M., Dwivedi, V., Khan, A. A., \& Mohammad, O. (2009). Efficacy of niosomal formulation of diallyl sulfide against experimental candidiasis in Swiss albino mice. Nanomedicine, 4(7), 713-724. 


\section{GRAPHICAL ABSTRACT}

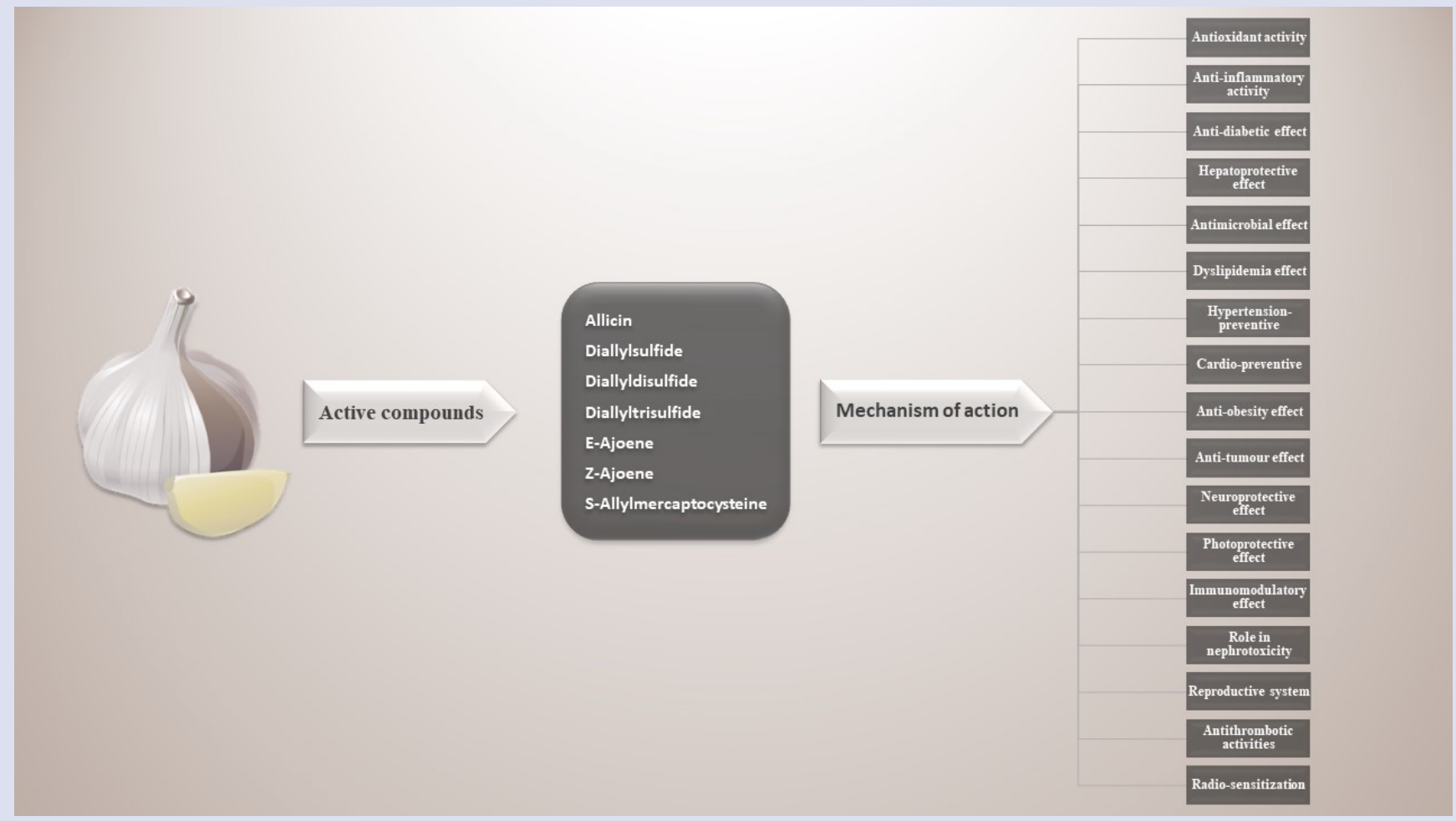

\section{ABOUT AUTHORS}

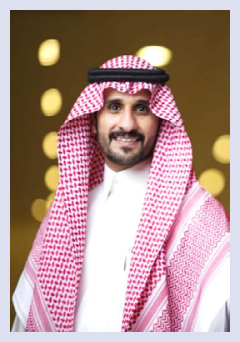

Faris Alrumaihi: Is as an Assistant Professor in the Department of Medical Laboratories and Vice Dean of College of Applied Medical Science for academic affairs, Qassim University, Kingdom of Saudi Arabia. His research interests include evaluation of the therapeutic potential of natural compounds in diseases management and expression pattern of genes linked to cancer development and progression. He has published several meaningful research papers in international repute journal and has presented his papers in many national and international conferences.

Cite this article: Alrumaihi F. Garlic and its Active Compounds: A Novel Strategy to Fight Diseases Through Modulating Biological Activities. Pharmacogn J. 2020;12(6):1463-74. 